\title{
Feasibility Study on IPMC Actuated Contractile Water Jet Thruster Body Contraction
}

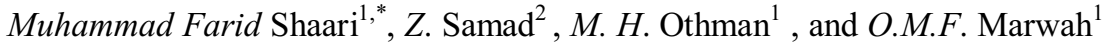 \\ ${ }^{1}$ Faculty of Mechanical and Manufacturing Engineering, Universiti Tun Hussein Onn Malaysia, Parit \\ Raja, 86400 Batu Pahat, Johor, Malaysia. \\ ${ }^{2}$ School of Mechanical Engineering, Universiti Sains Malaysia, 14300 Nibong Tebal, Pulau Pinang, \\ Malaysia.
}

\begin{abstract}
This research was conducted to investigate the feasibility of Ionic Polymer Metal Composite (IPMC) as the actuator for Contractile Water Jet Thruster (CWJT). The thrust that generated from the accelerated volume of ejected fluid depends on the IPMC actuator contraction performance. During this investigation, the variation of contraction frequency and nozzle aperture influence on the body deformation was carried out. The results of the experiments exhibit that the body contraction decreased tremendously from $0.05 \mathrm{~Hz}$ to $0.15 \mathrm{~Hz}$. The body contraction has no apparent decrement for more than $0.15 \mathrm{~Hz}$ of contraction frequency. Besides, larger nozzle aperture has relatively more body contraction than smaller nozzle aperture. These results show that the fixed actuation force and the contraction frequency have a significant influence on the CWJT body contraction.
\end{abstract}

\section{Introduction}

Contractile Water Jet Thruster (CWJT) is a thruster that inspired from the squid contractile mechanism [1]. The ejected water jet produces thrust in one direction and accelerates the thruster body in the opposite direction. It has low noise propulsion compared to the electric motor driven blade thruster if being actuated by smart actuator [2]. The function enables the CWJT to be adapted to quite or high sensitivity underwater task. IPMC utilizes low voltage and able to work in the water. However, it has a low actuation force which is between $5 \mathrm{gf}$ to $10 \mathrm{gf}$, depending on the type of electrode, actuator length and thickness [3, 4]. Thus, a feasibility study had been conducted on the contraction behaviour of the CWJT. The purpose of this study is to observe the CWJT volume contraction performance over time. In this research, two parameters were included in the observation which are the contraction frequency and the nozzle aperture. The nozzle aperture of the CWJT was varied in certain sizes and the IPMC actuator will contract the CWJT at different frequencies. The experiment was repeated for another nozzle apertures. Generally, the result of this study determined the relation between the volume contraction and the actuation frequency as well as the nozzle aperture. The relation between these parameters had been presented in graph

\footnotetext{
* Corresponding author: $\underline{\text { mdfarid@,uthm.edu.my }}$
} 
form in order to define the most influential parameters on volume contraction. The next section discusses the experimental setup and the result will be thoroughly discussed in the result and discussion section. Finally, the finding of this research is concluded in the last section.

\section{Materials and Method}

The CWJT was developed by using forms polyethylene (PE) film, which was then attached to a $3 \mathrm{~mm}$ thick acrylic plate and a nozzle. Generally, it has half tapered shape where the nozzle was placed at the sharp edge. The wider opening of the film was the inlet of the fluid. The PE film had been shaped by blow heating the PE film on a 3D printed mould. The heater temperature was recorded at $120^{\circ} \mathrm{C}$. The formed film was attached to the nozzle and both of them were then pasted on an acrylic plate. The IPMC actuators were fixed to the gold plated electrodes and its tip was pasted on the PE film (Figure 1). The gold plated electrodes were connected to a power supply (GW Instek PSM-3004) and the drive voltage was fixed at $4 \mathrm{~V}$ to ensure an optimum underwater IPMC actuation [5]. The contraction frequency, $f_{c}$ was determined by setting the IPMC actuation cycle time, $T_{a}$ in Arduino software version 1.0.5. The actuation cycle time is a time taken to trigger the IPMC actuator to make a complete upward and downward motion as presented in Figure 2. The ejected fluid from the actuation was calculated from the volume difference of this displacement. The reversible IPMC actuation was obtained by using H-bridge L239D and Arduino UNO microcontroller. There were 10 sets of contraction frequencies between $0.05 \mathrm{~Hz}$ and $0.50 \mathrm{~Hz}$ had been put understudies. This frequency range had been selected based on the optimum IPMC actuator character [6,7]. Table 1 shows the sets of the contraction frequency that utilized in the experiments. The relation between contraction frequency and the actuation cycle time can be presented as Equation 1.

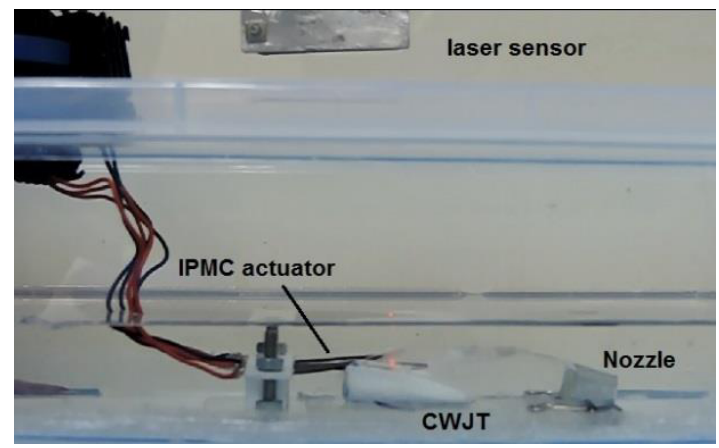

Fig. 1. Experimental setup. 


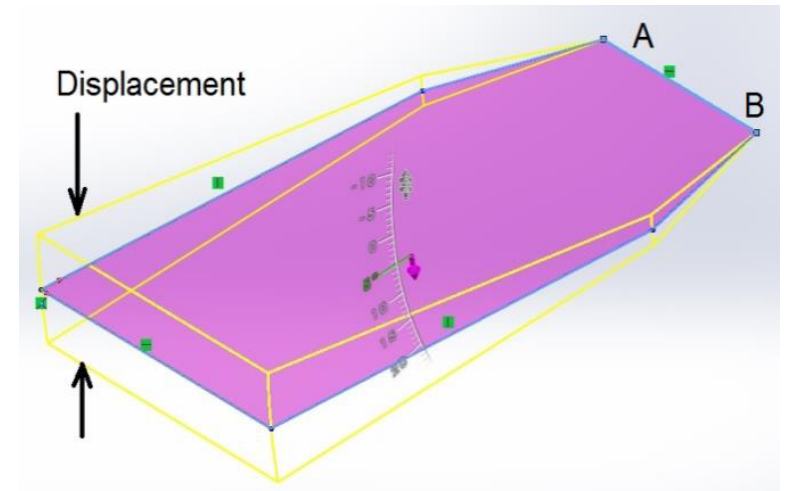

Fig. 2. Actuation of the IPMC.

Table 1: Frequency setting.

\begin{tabular}{|c|c|}
\hline 1 cycle time (s) & Frequency $(\mathbf{H z})$ \\
\hline 2 & 0.500 \\
\hline 4 & 0.250 \\
\hline 6 & 0.167 \\
\hline 8 & 0.125 \\
\hline 10 & 0.100 \\
\hline 12 & 0.083 \\
\hline 14 & 0.071 \\
\hline 16 & 0.063 \\
\hline 18 & 0.056 \\
\hline 20 & 0.050 \\
\hline
\end{tabular}

$$
f_{c}=\frac{1}{T_{a}}
$$

Observation on the body displacement was measured using laser displacement sensor (Panasonic HG-C1100). The laser was pointed to the fluid inlet area to measure the maximum displacement of the CWJT as shown in Figure 2. The obtained data were recorded in Signal Express software through National Instruments DAQ card NI USB 6009. Once the displacement data were recorded for all contraction frequencies, the experiment was repeated for another nozzle aperture size between $4 \mathrm{~mm}$ and $12 \mathrm{~mm}$. The volume difference, because of the actuation was calculated by applying Pappus-Guldinus Theorem as described in Equation 2,

$$
V_{c}=2 \pi \bar{y} A_{c}
$$

where $V_{c}$ is the contraction volume, $\tilde{y}$ is the distance between the centroid and the rotation axis which is in this case is the line along point $\mathrm{A}$ and point $\mathrm{B}$ in Figure 2. $A_{c}$ is the rotating 
surface which is affected by the actuation. $2 \pi$ refers to the rotation angle which means complete $360^{\circ}$ angle. Therefore, the displacement data gained in the experiment utilized to determine the angle of rotation. This calculation had been achieved by using tangent formula whereas the axis of rotation. The acquired degrees were then converted into radian degree before it could be applied in the Pappus Guldinus Theorem.

\section{Results and Discussion}

The relation between CWJT displacement and nozzle aperture is depicted in Figure 3. The results show that the CWJT body displacement increases as the nozzle aperture became wider. However, the displacement increment is quite small which is between $11 \%$ and $70 \%$, depending on the contraction frequency. Higher contraction frequency has low displacement while lower contraction frequency has higher displacement. This is due to the character of the IPMC actuator itself [8]. Lower contraction frequency allows more water swell into the one side of the IPMC to actuate it. Higher contraction frequency has limited time to absorb water for actuation. The results also show that the displacement increment trend increases exponentially as the contraction frequency decreases. This displacement data had been utilized to measure the CWJT volume contraction using Equation 2. Based on the calculated results, the relation between contraction volume and the contraction frequency had been identified as exhibited in Figure 4.

Generally, the graph shows that the relation between CWJT contraction volume and the contraction frequency has the same trend which is an exponential decay trend. The contraction volume decreases tremendously started from $0.05 \mathrm{~Hz}$ to $0.15 \mathrm{~Hz}$. The reduction of contraction volume within this range is approximately 6 to 7 times. The highest record of the contraction volume was $717 \mathrm{~mm}^{3}$ at $0.05 \mathrm{~Hz}$. At the contraction frequency of more than $0.15 \mathrm{~Hz}$, the volume contraction started to decrease in constant linear trend. At this range, the contraction volume was recorded between $100 \mathrm{~mm}^{3}$ and $300 \mathrm{~mm}^{3}$. In this graph, the nozzle aperture had shown no significant influence on the contraction volume except for contraction frequency within $0.2 \mathrm{~Hz}$ to $0.3 \mathrm{~Hz}$. Based on this observation, it could be concluded that the contraction frequency has more impact on volume contraction if relatively compared to the nozzle aperture size despite of the nozzle aperture increases by almost $67 \%$ from $4 \mathrm{~mm}$ diameter to $12 \mathrm{~mm}$ diameter. This condition occurred as the consequence of the low actuation force by the IPMC actuators. In spite of the significant influence by the contraction frequency, others vital factors for volume deformation were the actuation acceleration and force. Thrust, which can be derived from the momentum equation is highly affected by the rate of ejected volumetric fluid. 


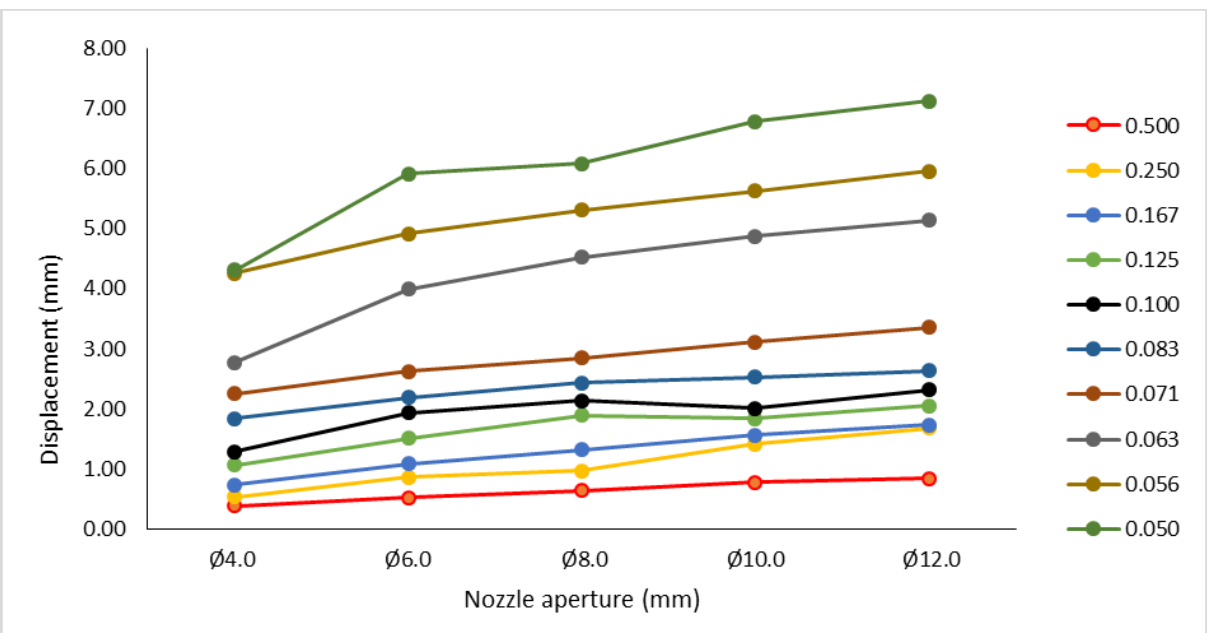

Fig. 3. CWJT body displacement measured by laser sensor at different nozzle aperture and contraction frequency.

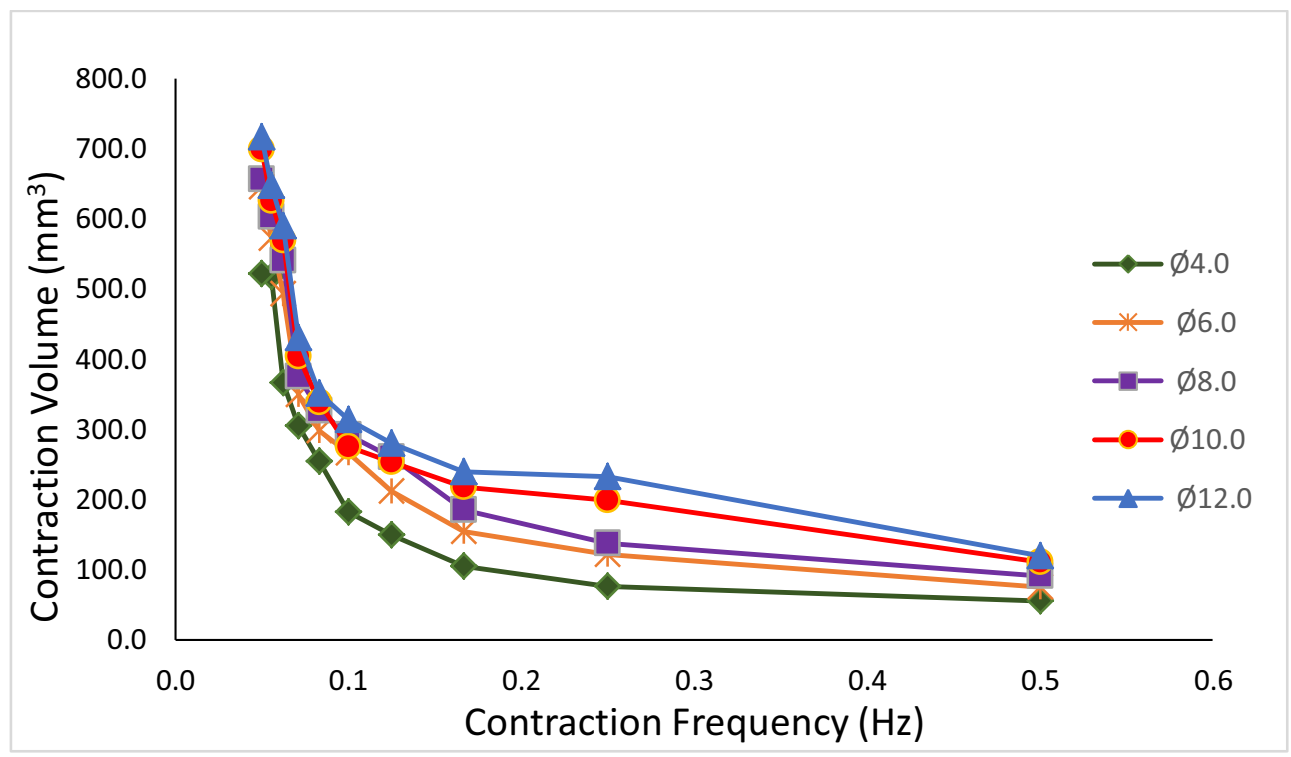

Fig.4. Contraction volume at different contraction frequency.

\section{Conclusion}

In this research, the measurement of contraction volume is essential to determine the feasibility of the CWJT contraction. The relationship between the contraction frequency and the contraction volume has shown that there are tremendous decreases of contraction volume between $0.05 \mathrm{~Hz}$ and $0.15 \mathrm{~Hz}$. On the other analysis, nozzle aperture has no significant influence on the contraction volume as its value has not changed much despite of the nozzle aperture difference. Meanwhile the contraction frequency depends on the 
IPMC actuation force. These two parameters were measured by single actuation force. The result might change if higher IPMC actuation force will be applied.

The author would like to compliment Universiti Tun Hussein Onn Malaysia for sponsoring this project via IGSP grant vot no. U257 and providing facilities to complete this research.

\section{References}

1. M.F. Shaari, Z. Samad, Applied Mechanics and Materials, 490, 1099 (2014)

2. M.F. Shaari, C.J. Jun, Z. Samad, IEEE International Conference on Robotics Biomimetics, \& Intelligent Computational System (2013)

3. A. Barber, J. Najem, L. Donald, J. Blotman, EAPAD, 7976, (2011)

4. L. Shi, S. Guo, S. Mao, M. Li, K. Asaka, Int. J. Adv. Robot. Syst., 10, 1 (2013)

5. M.F. Shaari, S.K. Saw, Z. Samad, Applied Mechanics and Materials, 575, 716 (2014)

6. C.K. Chung, P.K. Fung, Y.Z. Hong, M.S. Ju, C.C.K. Lin, T.C. Wu, Sensor Actuators B. Chem., 117, 367 (2006)

7. S.G. Lee, H.C. Park, Surya D. Pandita, Y. Yoo, Int. J. Control Autom. Syst., 4, 748 (2006)

8. E. Malone, H. Lipson, Rapid Prototyp. J., 12, 244 (2006) 